\title{
Nonclinical Pregnancy Results Domain
}

National Cancer Institute

\section{Source}

National Cancer Institute. Nonclinical Pregnancy Results Domain. NCI Thesaurus. Code C102678.

A subject domain utilized for the submission of information encompassing and representing data, vocabulary or records related to nonclinical pregnancy results. 